\title{
La cara oculta del comercio: Las redes sociales. Caso quesilleras de Nagarote
}

\author{
Martha C. Palacios $\mathrm{N}^{1}$, Marisela Benavides ${ }^{2}$ y Vania Páiz ${ }^{2}$ \\ 1. Departamento de Ciencias Sociales, Facultad de Humanidades. Universidad Centroamericana (UCA). Apartado 69. Managua, \\ Nicaragua.e-mail:marthap@ns.uca.edu.ni \\ 2. Egresadas de la carrera de Trabajo Social, Facultad de Humanidades, Universidad Centroamericana (UCA). Apartado 69. Managua, \\ Nicaragua.
}

Recibido: abril 2005 / Aceptado: junio 2005

EL PRESENTE ARTículo SE BASA EN LOS RESUltados DE Un estudio que tuvo como propósito analizar las redes sociales que se estructuran en el comercio de los quesillos de Nagarote, para identificar alternativas que contribuyan a su sostenibilidad. Los hallazgos de la investigación muestran que, detrás del comercio, hay todo un proceso organizativo en el que confluyen una serie de elementos: desde lo económico, se conforman cadenas de producción y comercialización; y desde lo social, hay múltiples interrelaciones entre los distintos actores que intervienen, constituyendo redes sociales complejas y simples, que se basan en prácticas sociales donde la cercanía física, la confianza y el interés mutuo son fundamentales. Tratándose de una actividad que se desarrolla en un contexto nacional caracterizado por condiciones adversas, se hizo un análisis que permitió reconocer factores que, por su complejidad e influencia, pueden ser considerados como amenazas o como oportunidades.

Palabras clave: sociología rural, mujeres-aspectos socioeconómicos, quesoscomercio

\section{Introducción}

El quesillo es quizás el producto más folklórico de los derivados de la leche. Difícilmente puede encontrarse, al menos en la región del Pacífico del país, a un nicaragüense que no haya degustado o, siquiera, oído hablar de él: "es sabroso", "se vende en bolsa, sea doble o sencillo", "es de trenza o redondo", "se puede comer en la calle, en el carro, en la casa, en el colegio, en la playa”. Es uno de los productos más populares. Y, el más conocido, es el quesillo de Nagarote.

Nagarote es considerado la "cuna" del quesillo. Es en ese municipio del departamento de León, ubicado a 40 kilómetros al occidente de Managua, donde se encuentran personas 
que dan referencia oral de la primera vez que se le ocurrió, en 1912, a Doña Socorro Munguía "pasar" una cuajada por agua hirviendo hasta darle la consistencia deseada y, luego, ofrecerla como un nuevo producto, servida con una tortilla de maíz, a los pasajeros del ya desaparecido Ferrocarril del Pacífico de Nicaragua que, procedente de Carazo y Masaya, luego de pasar por Managua, se dirigían a León, con destino final en el Puerto de Corinto.

Actualmente, la producción y comercialización del quesillo de Nagarote es una actividad con la que muchas mujeres sostienen a sus familias y contribuyen a que productores de leche, comercializadores de queso, elaboradoras de tortillas y otros tengan un mercado asegurado de sus respectivos productos. Es decir, en buena medida, dinamizan la economía de su Municipio.

El interés de este artículo sobre el comercio de los quesillos producidos en Nagarote es mostrar de qué forma la producción y comercialización del producto subsiste gracias a las redes que se tejen entre actores sociales, las que se encuentran invisibilizadas, y cuya existencia se comprobó a través de un estudio que permite aprender lecciones.

Nicaragua, como los demás países Centroamericanos, realiza grandes esfuerzos para lograr una inserción exitosa en las corrientes globales que traen consigo la creación del área de libre comercio, por lo que se requiere considerar factores endógenos, entre los que se pueden incluir las prácticas tradicionales de la producción y comercialización de bienes de consumo. Los quesillos producidos en Nagarote pueden ser un ejemplo.

Vemos a la cultura como potencial humano, que debe ser aprovechado por los países en "vías de desarrollo", centrándose en estas capacidades como un medio para fortalecer la presencia y el poder de negociación ante un mundo que avanza y se desarrolla tecnológicamente.

El objetivo de la investigación fue realizar un primer estudio de la producción y comercialización de los quesillos de Nagarote, para identificar alternativas de sostenibilidad. Esa actividad económica es desarrollada por mujeres que han implementado unas estrategias propias, que les permiten mantenerse en el mercado, a pesar de las difíciles condiciones económicas y sociales del contexto.

Para el Trabajo Social, el estudio de las redes sociales tiene un gran valor, ya que como profesión, se propone potenciar a las personas para la búsqueda de opciones que les permitan mejorar sus condiciones de vida, partiendo del conocimiento y explicación de la vida cotidiana, para gestionar políticas que contribuyan al desarrollo económico y social.

\section{Metodología de la investigación}

El método que se desarrolló para esta investigación es el análisis de caso, con el propósito de conocer el comportamiento concreto de las productoras-comercializadoras de los quesillos de Nagarote, como una expresión de diversas estrategias económicas que se desarrollan en los sectores populares del país. 
Inicialmente, se realizó una visita a los ocho establecimientos localizados a lo largo de la carretera Managua-León, para dar a conocer el objetivo de la investigación, conocer el funcionamiento general de los establecimientos, obtener una primera aproximación al número de productoras y definir una muestra. Se usó como instrumento la entrevista, para lo que se elaboró una guía de entrevista que permitió orientar la conversación, mantener la buena comunicación y ánimo de las entrevistadas y obtener respuestas amplias. Posteriormente, utilizando esa misma técnica, se profundizó en los procesos desarrollados.

También se recurrió a la observación in situ: ver y escuchar a la gente en su contexto real donde llevan a cabo sus actividades de cara al fenómeno investigado. Igual procedimiento se utilizó con las productoras que venden de forma ambulante. Las productoras de quesillo entrevistadas son las más representativas en el proceso de producción y comercialización del producto.

Otras entrevistas estuvieron dirigidas a los proveedores de los insumos: leche, tortilla, maíz etc.; y funcionarios de instituciones locales: Alcaldía de Nagarote, Ministerio de Salud y Casa de la Cultura. Además, se realizó una revisión bibliográfica, como una técnica de investigación documental, puesto que no es recomendable iniciar un estudio sin un referente teórico y un conocimiento a priori de los objetivos de investigación.

Con base en los planteamientos de distintos autores que desarrollan la teoría de Redes Sociales, se definieron las variables a estudiar con relación a esta categoría. Estas fueron: actores sociales que integran las redes; lazos relacionales existentes (fuertes, débiles); vínculos entre los actores sociales; roles de los actores; y responsabilidades individuales y colectivas.

Para conocer lo relativo al comercio del quesillo, se precisaron las variables siguientes: identificación de mercados: oferta, demanda; fijación del precio: producción, comercialización; canales de comercialización establecidos; número de trabajadores: mano de obra empleada; y consumidores: características, ubicación.

Con el fin de caracterizar el entorno socio-económico, se realizó un análisis de distintas variables de índole económica y social que afectan a la sociedad nicaragüense y que pueden constituirse en Amenazas y Oportunidades, para el funcionamiento de las cadenas de comercialización y de las redes sociales que se estructuran alrededor del producto.

El análisis de la información obtenida alrededor de las variables señaladas, permitió reconocer cuatro cadenas y diversas redes en el proceso que, si bien tienen elementos comunes, otros son muy particulares y dan perfil propio a cada una de las cadenas y redes identificadas.

\section{Hallazgos de la investigación}

\subsection{Organización para la comercialización}

A fin de determinar las formas organizativas existentes en la producción y comercialización 
del quesillo, el estudio se apoyó en la lógica de las cadenas, considerándolas como la suma y vinculación entre actores involucrados en las distintas operaciones que se dan en todo el proceso: abastecimientos, producción y comercialización, hasta que llega al consumidor final en forma de producto elaborado (Parrilli, 2001:140).

La definición de comercio utilizada dice: "es la actividad que se realiza dentro del mercado y es aplicada a las relaciones económicas, transacciones de cambio o trueque, también al trato social, al intercambio de comunicaciones entre personas, en situación de grupo y cara a cara, usualmente en el supuesto de una ganancia en valores por ambos lados, la cual puede ser mental, verbal o afectiva y en uso corriente" (Pratt,1994:49).

Con este estudio, se identificaron cuatro cadenas para la comercialización de los quesillos producidos en Nagarote en el mercado nacional (ver ilustración 1), cada una de ellas con sus peculiaridades: hay quienes venden en establecimientos o ranchos típicos; unas se dedican exclusivamente al quesillo; otras tienen una variedad de productos, un menú en donde ofrecen este platillo de tradición cultural; y en otra cadena, comercializan en distintas 100 ciudades del Pacífico mediante venta ambulante y puestos fijos (carretones), ubicados en centros de compras.

Cadena 1

Cadena 2

Cadena 3

Cadena 4

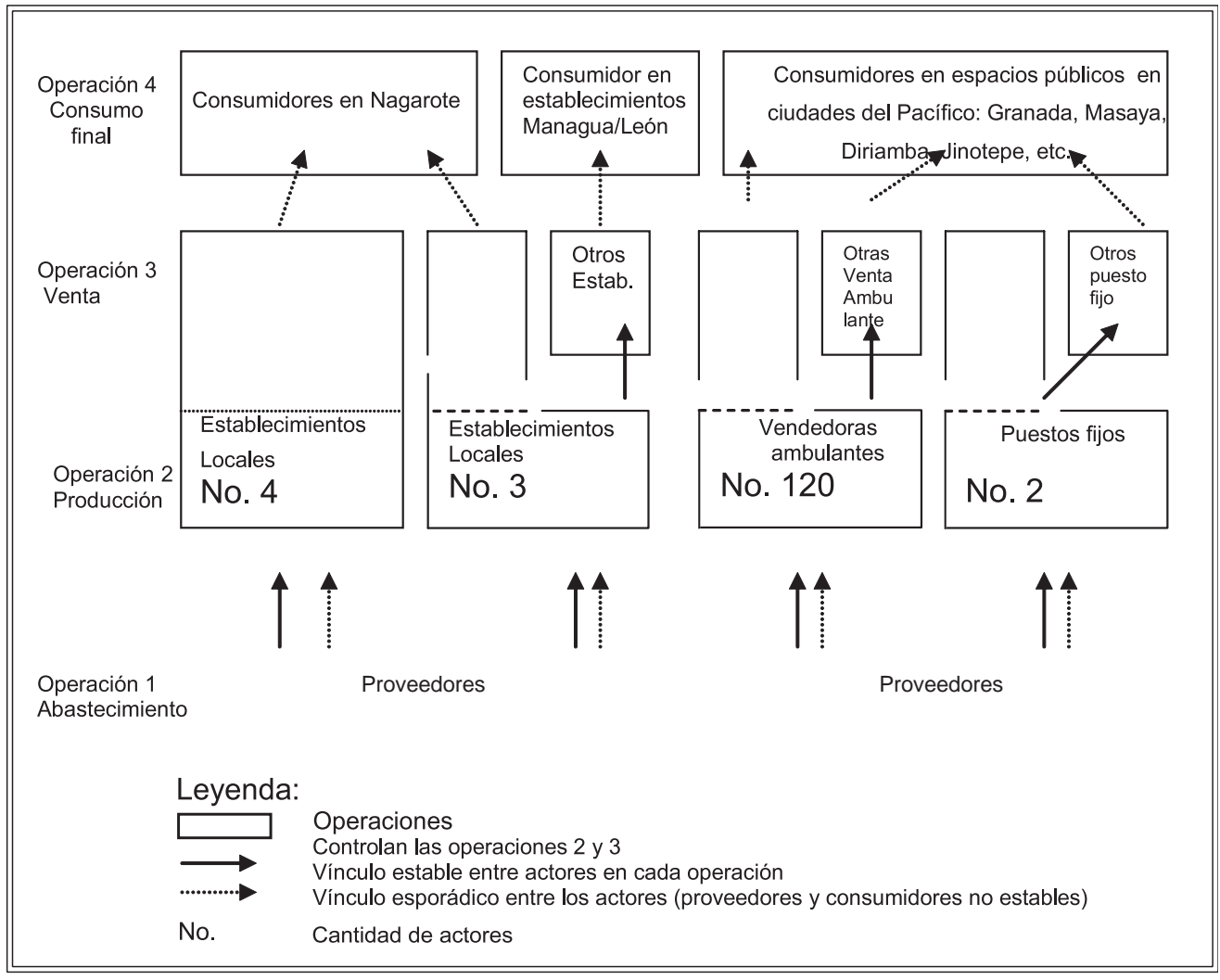

Ilustración 1. Cadenas de comercialización del quesillo 


\section{2. ¿Cuánto cuesta un quesillo de Nagarote?}

En la actividad comercial del quesillo, las mujeres establecen el precio del producto de forma empírica, pues no utilizan ningún método contable. Por ello, para fijar el precio para el estudio, se realizó un análisis económico, que consistió en conocer que factores inciden en el precio de los quesillos, porque hay diferencias en cada cadena (ver cuadro 1).

Cuadro 1. Precios al consumidor según el tipo de quesillo y cadena de producción

\begin{tabular}{|c|c|c|c|c|}
\hline Precios & Cadena 1 & Cadena 2 & Cadena 3 & Cadena 4 \\
\hline Redondos & No elaboran & $\mathrm{C} \$ 7.00$ & $\mathrm{C} \$ 3.00$ & $\mathrm{C} \$ 7.00$ \\
\hline Trenzas & $\mathrm{C} \$ 5.00$ & $\mathrm{C} \$ 14.00$ & $\mathrm{C} \$ 5.00$ & $\mathrm{C} \$ 10.00$ \\
\hline
\end{tabular}

Fuente: Entrevistas realizada a productores, agosto 2002.

El cuadro 2 muestra una comparación del costo de producción de un quesillo de trenza y su precio al consumidor en las 4 cadenas identificadas. La variación de los precios y costos corresponde a la calidad del producto ofertado, tamaño y consistencia.

Cuadro 2. Comparación de costos de producción y precio al consumidor del quesillo de trenza

\begin{tabular}{|c|c|c|c|c|}
\hline $\begin{array}{c}\text { Quesillos de } \\
\text { Trenzas }\end{array}$ & Cadena 1 & Cadena 2 & Cadena 3 & Cadena 4 \\
\hline Costo de producción & $\mathrm{C} \$ 3.21$ & $\mathrm{C} \$ 4.25$ & $\mathrm{C} \$ 2.26$ & $\mathrm{C} \$ 4.33$ \\
\hline Precio al consumidor & $\mathrm{C} \$ 5.00$ & $\mathrm{C} \$ 14.00$ & $\mathrm{C} \$ 5.00$ & $\mathrm{C} \$ 10.00$ \\
\hline
\end{tabular}

Fuente: Entrevistas realizada a productores, agosto 2002.

El cálculo del costo de producción se efectuó sobre la base del precio unitario de los insumos requeridos para la elaboración y comercialización de los quesillos (ver cuadro 3), y la cantidad de producto que obtienen de ellos. Como referencia se tomó: una libra de cuajada simple, una libra de crema, una libra de cebolla, tortilla, sal y vinagre y otros productos como combustible, bolsas plásticas y servilletas. 
Cuadro 3. Costos de los insumos

\begin{tabular}{|l|c|c|c|}
\hline $\begin{array}{c}\text { Insumos utilizados para la } \\
\text { elaboración de quesillos }\end{array}$ & $\begin{array}{c}\text { Unidad } \\
\text { de } \\
\text { Medida }\end{array}$ & Cantidad & $\begin{array}{c}\text { Costo } \\
\text { Unitario } \mathbf{C \$}\end{array}$ \\
\hline Cuajada & libra & 1 & 13.50 \\
\hline Crema & libra & 1 & 11.50 \\
\hline Cebolla & libra & 1 & 4.00 \\
\hline Repollo & ${ }^{*}$ & 1 & 10.00 \\
\hline Vinagre & ${ }^{*}$ & ${ }^{*}$ & 4.00 \\
\hline Sal & libra & 1 & 4.00 \\
\hline Tortillas & ${ }^{*}$ & 3 & 1.00 \\
\hline Leña & manojo & 1 & 10.00 \\
\hline Gas butano & Cilindro & 1 & 87.00 \\
\hline Insumos utilizados para la venta & & & \\
\hline Bolsas plásticas & paquete & 100 & 5.00 \\
\hline Servilletas & paquete & 100 & 7.00 \\
\hline
\end{tabular}

Fuente : entrevistas realizadas a productoras,agosto 2002

\subsection{Actores sociales en la comercialización del quesillo de Nagarote}

En todo el proceso de producción y comercialización del quesillo, se identifica la presencia de distintos actores que son "entidades sociales, sujetos de los vínculos de las redes sociales. Son de diversos tipos: individuos, unidades colectivas sociales, etc” (Lozares, 1996: 108), cuya participación es fundamental para el desarrollo de esta actividad económica. En la ilustración 2 se presenta una idea del conjunto de actores que constituyen la cadena de comercialización del quesillo.

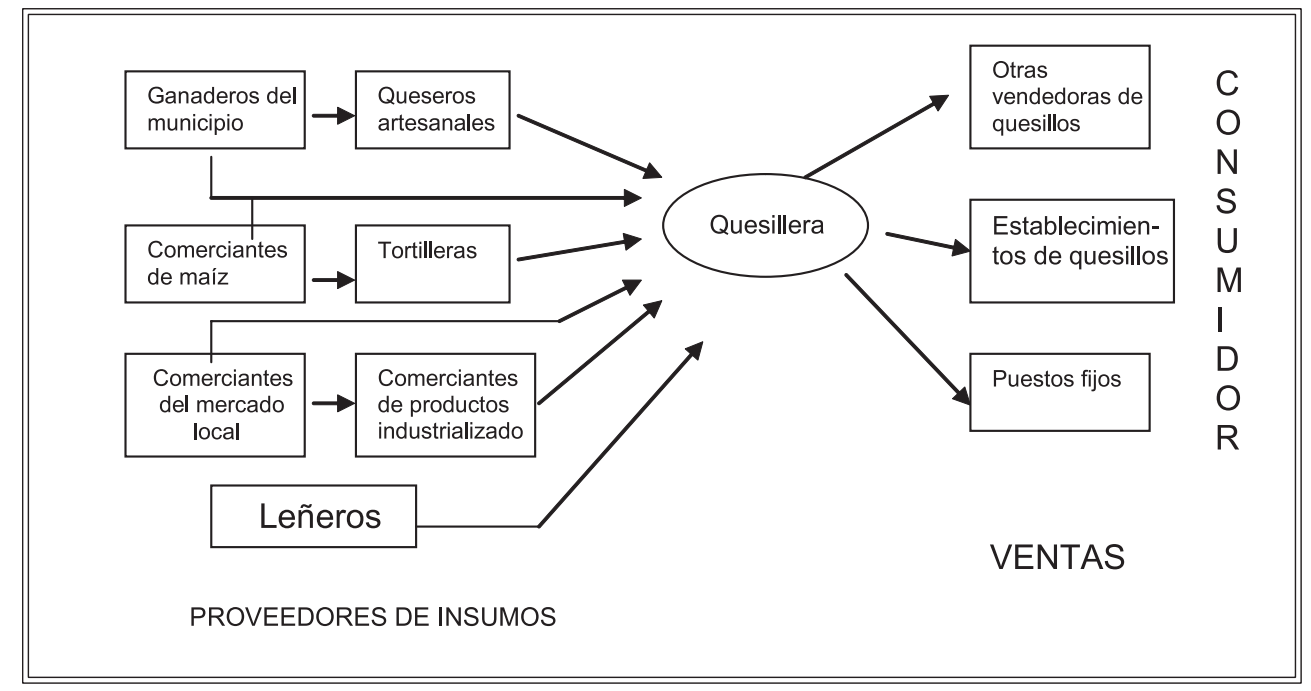

Ilustración 2. Actores involucrados en las cadenas de quesillo 
Posteriormente, con el análisis de la información y el respaldo del marco teórico conceptual, se identificaron los diferentes tipos de redes, que se categorizaron como complejas y simples, dependiendo de la cantidad e intensidad de conexiones en que se involucran los diversos actores presentes. Las distintas prácticas sociales conocidas permitieron entender las redes que se entretejen en las distintas etapas del proceso de producción y comercialización.

\section{Redes sociales en la producción y comercialización del quesillo de Nagarote}

Para este estudio, se entiende como redes "el conjunto bien delimitado de actores, individuos, grupos y organizaciones, comunidades y sociedades vinculadas unas con otras a través de una relación o conjunto de relaciones sociales como entidades sociales" (Lozares, 1996: 108).

$\mathrm{Al}$ analizar las cadenas productivas, se evidenciaron los lazos que se establecen para llevar a cabo las distintas operaciones del proceso productivo. Sin embargo, se estima conveniente poner en primer plano las relaciones sociales que se entretejen para conformar redes.

En la amplia trama de relaciones interpersonales existentes en la producción y comercialización del quesillo, se identifican diversas redes. De ellas, unas en lo que puede considerarse el nivel macro del proceso: las cadenas. Es decir, cada cadena conforma en su conjunto una red; a nivel micro, las que se producen con el establecimiento de vínculos intra cadenas, entre actores que intervienen en alguna de las operaciones de una cadena; $y$, finalmente, hay redes integradas por actores de distintas cadenas.

Cuadro 4. Clasificación de redes identificadas en la producción y comercialización del quesillo

\begin{tabular}{|l|l|l|}
\hline $\begin{array}{l}\text { Tipo de } \\
\text { redes }\end{array}$ & \multicolumn{1}{|c|}{ Características generales } & Redes identificadas \\
\hline Complejas & $\begin{array}{l}\text { Son policéntricas: distintos actores juegan un } \\
\text { rol central con relación a otros; están } \\
\text { formadas por un considerable número de } \\
\text { personas; los vínculos existentes entre } \\
\text { actores son de origen variado: parentesco, } \\
\text { amistad, trabajo, vecindad, comercialización, } \\
\text { etc.; hay una amplia dispersión al no darse } \\
\text { conexión directa entre algunos actores. Los } \\
\text { lazos establecidos son fuertes en ciertos } \\
\text { casos y débiles en otros. }\end{array}$ & Cadenas 1,34 \\
\hline Simples & $\begin{array}{l}\text { Son egocéntricas: un actor tiene un rol central; } \\
\text { se establecen relaciones diádicas; el número } \\
\text { de miembros es menor con relación a las } \\
\text { complejas; la dispersión es mínima por cuanto } \\
\text { el vínculo es directo entre actores; los lazos } \\
\text { son más fuertes por existir parentesco y un } \\
\text { mayor grado de confianza formado en la } \\
\text { sostenibilidad en el tiempo de dicha relación. }\end{array}$ & $*$ Entre productoras de quesillo y tortilleras. \\
\hline
\end{tabular}

Fuente: elaboración propia. 


\subsection{Redes complejas}

Se clasificaron como redes complejas las cuatro cadenas, que constituyen una macro-red, puesto que están integradas por muchos actores que intervienen en los distintos eslabones de las cadenas, desde el abastecimiento hasta la comercialización del producto. Más de un actor asume un papel central con relación a otros, pues de él o ella depende un número considerable de personas y es, además, quien establece las normas que deben cumplirse para la realización de sus transacciones (cuadro 4).

En la macro-red conformada por la cadena 3, pudo detectarse que hay un productor de leche y siete queseros a cuyo alrededor se aglutina un grupo importante de quesilleras. Un quesero tiene hasta 12 productoras de quesillo a quienes provee de cuajada. Una situación similar se da con las 120 productoras, muchas de las cuales agrupan a su alrededor a cinco o seis vendedoras ambulantes (batelleras).

Los vínculos existentes en este tipo de red son de diversa índole: amistad, parentesco, 104 vecindad y otros de tipo meramente comercial. El largo tiempo de trabajo desarrollado conjuntamente les ha generado confianza, y esto permite llevar a cabo sus transacciones, incluyendo que las productoras puedan acceder a los insumos aun cuando no dispongan de dinero. Los lazos establecidos entre los actores son fuertes en algunos casos y débiles en otros. Esto sucede entre la productora y el consumidor que, por lo general, se limita a la compra-venta.

Los lazos que se dan entre productoras y queseros, por la mutua conveniencia en las transacciones, son considerados como fuertes, pues se trata en ambos casos de desarrollar sus principales actividades económicas. Además, se han llegado a crear vínculos de solidaridad y amistad. Inclusive, hay queseras que buscan nuevos sitios para que las productoras con las que trabajan abran mercado.

Con relación a los lazos que se establecen entre la proveedora de tortilla y la quesillera a la que abastece, pueden calificarse de fuertes. Algunas de ellas tienen varios años de realizar sus transacciones. Además, hay una conveniencia mutua, porque las tortillas deben cumplir con los requisitos establecidos por las productoras de quesillo en cuanto a tamaño y consistencia, para garantizar la calidad del platillo. En consecuencia, las señoras tortilleras desean quedar bien con las quesilleras para asegurar sus ventas diarias.

\subsection{Redes simples}

Este tipo de redes son las más comunes en la comercialización del quesillo. No necesariamente están dentro de una cadena, sino que las hay integradas por actores que pertenecen a distintas cadenas. En comparación con las redes complejas, el tamaño y la dispersión de las redes simples son más pequeñas: los vínculos entre los actores son directos, los lazos que los unen son mayoritariamente fuertes y el número de miembros es menor. Hay un actor que juega un papel central (cuadro 4). 
Por esta razón, se considera una red egocéntrica con relaciones diádicas que, según Lozares (1996:109), están conformadas por un "par de actores y el posible lazo entre ambos". El actor principal en esta red podría ser un quesero o una productora que establece relaciones diádicas con cada uno de los miembros que la integran. De igual manera ocurre con las productoras y sus vendedoras.

\section{Red entre proveedores de cuajada y productoras}

En esta relación se crea un ambiente de familiaridad y confianza por ambas partes. La confianza "incluye las siguientes componentes: a) capacidad y deseo para entablar una relación de intercambio recíproco; b) voluntad de cumplir con las obligaciones implícitas en dicha relación; c) familiaridad mutua suficiente para servir de base a un acercamiento con probabilidad de no ser rechazado" (De Lomnit,1985: 28).

Un punto importante en esta red es que cada quesero teje su propia red, ejerciendo un papel determinante sobre la organización en la que está inmerso, pues es él quien toma todas las decisiones, acuerdos y arreglos para el buen funcionamiento.

Una de las normas existente en esta red consiste en el cumplimiento de los arreglos de pago, factor que garantiza a la productora su abastecimiento de cuajada simple de parte del quesero en la época de verano, cuando la producción de leche se reduce y, por ende, la de cuajada. Cuando las productoras incumplen con lo establecido, surgen conflictos en las transacciones entre el proveedor y la quesillera. Para la solución de estas situaciones, a las clientas fijas se les extiende el plazo para pagar, o la deuda se cancela en cuotas bajas.

Las pequeñas productoras que integran estas redes habitan, generalmente, en Nagarote, lo que les facilita la frecuencia de sus contactos con los proveedores de cuajada. Sin embargo, llegan de otros municipios mujeres que también compran cuajadas para elaborar quesillos y comercializarlos, constituyéndose en competencia para el abastecimiento.

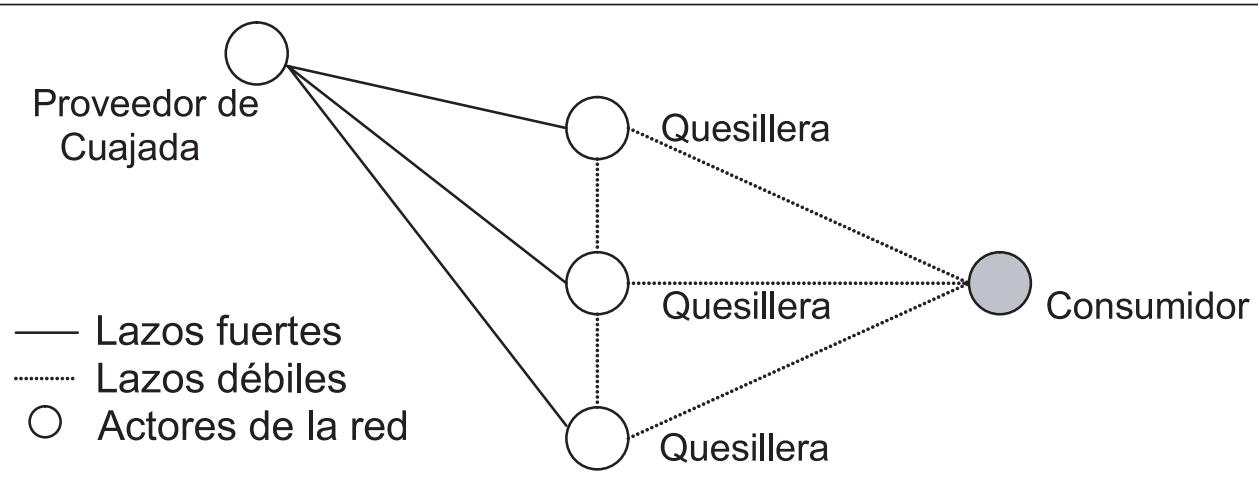

llustración 3. Red simple: proveedor- productora-vendedora 
Como se muestra en la ilustración 3, los lazos que en este caso se han establecidos son catalogados como fuertes, dada las frecuencias de intercambios, la constancia de trabajo y el cumplimiento de las normas establecidas.

\section{Red entre pequeñas productoras y comercializadoras}

Está formada por productoras de quesillo que interactúan con otras mujeres vendedoras, con quienes tienen vínculos familiares o de amistad, que les permite la formación de redes, haciendo posible sus intercambios de mercado. El objetivo fundamental de este tipo de red es incrementar el volumen de venta con el fin de obtener mayores ingresos para la satisfacción de sus necesidades.

Este es el caso de la señora Nidia Pérez (ilustración 4), que pertenece a la cadena 3 de comercialización integrada por vendedoras ambulantes. Es considerada una de las quesilleras con mayor capacidad de producción, lo que le permite jugar un papel determinante dentro de la red, porque ella se dedica a la producción y, posteriormente, abastece a sus vendedoras 106 que son sus tres hijas y una amiga de la familia, que empezó trabajando en la producción de quesillos con la señora Nidia y, posteriormente, decidió ir a vender.

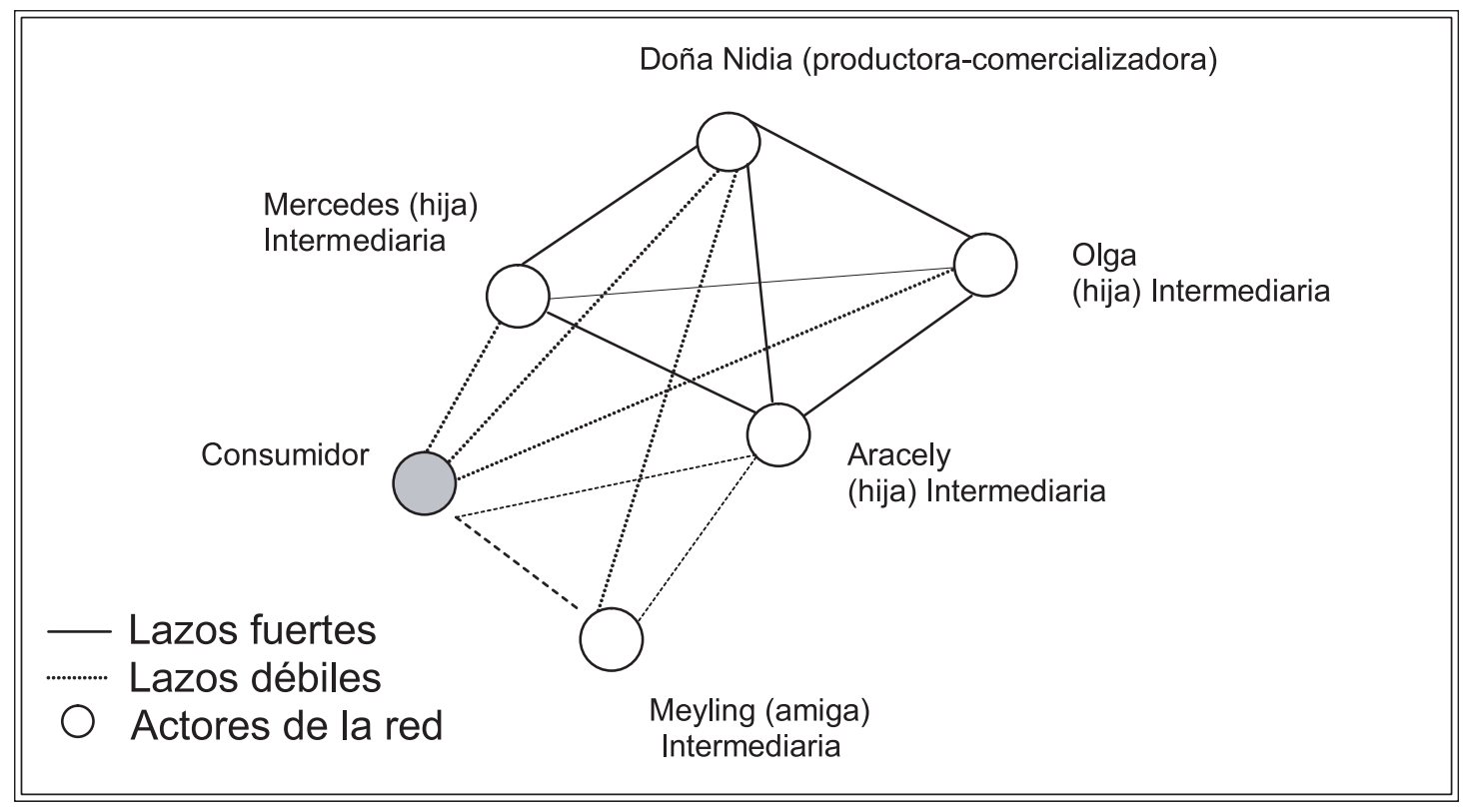

Ilustración 4. Red simple productora-vendedora

En la ilustración anterior se muestran los lazos fuertes y débiles entre las distintas actoras que conforman la red. Existen lazos fuertes en la comercialización del quesillo, pues mantienen una idea común sobre esta actividad. La madre ha trasmitido a sus hijas el pensamiento de la venta de quesillos como una opción para el sostén económico presente y futuro. Por lo tanto, las hijas se han integrado a una experiencia comercial que parte de un vinculo 
familiar, generándose un proceso de socialización en el que se interiorizan las normas y valores que se definen para la existencia y el funcionamiento de la red.

Esta red se clasifica como egocéntrica, pues es la señora Nidia la que establece normas que sirven de base a los acuerdos con sus vendedoras. Además, es responsabilidad de la productora entregar la venta completa, es decir: el producto a comercializar, más los recipientes para colocarlo, bateas, delantal, dinero para el pago del transporte y, en ocasiones, ubica a sus vendedoras en un puesto donde ella vendió previamente e hizo su clientela.

Los lazos fuertes que hay en este tipo de redes se evidencian en su composición y escasa dispersión, puesto que se trata de miembros de una misma familia que se relacionan directamente y de forma cotidiana para realizar acciones propias de la red: hay una cercanía social que facilita los intercambios.

Se puede decir que los lazos existentes entre actoras hacen posible la formación de una red de solidaridad, donde se dan relaciones de ayuda en situaciones de dificultad para llevar a cabo la actividad comercial, con beneficios para ambas partes.

Meyling, a través de su amistad que inició con Araceli, logró integrarse a la red comenzando con el trabajo en la producción; posteriormente, pasa a vendedora, existiendo entre ambas lazos fuertes dada su cercanía física. Sin embargo, entre Meyling y el resto de miembros de la red, los lazos son débiles porque la única relación que existe es la estrictamente comercial. En caso de no cumplir con las disposiciones de Doña Nidia, ella puede prescindir de sus servicios y buscar otras jóvenes interesadas en obtener ingresos.

Con los consumidores, generalmente se establecen lazos débiles, pues se reduce a un trato esporádico de compra y venta que permite a las quesilleras un mercado para los quesillos. Lazos de este tipo, aunque se consideren débiles, son sumamente útiles, ya que permiten a las productoras y vendedoras vincularse con otros miembros de la sociedad y obtener nuevos conocimientos sobre los hábitos de consumo y formas de relacionarse con las personas; igualmente, reciben información muchas veces importante para su actividad, como nuevas plazas de venta. Aunque de manera general se valoran estas conexiones como débiles, pueden llegar a transformarse en fuertes, siempre que se mantengan en el tiempo y entre ambas partes haya certeza de que se satisface una necesidad (vender y consumir).

De esta forma, las productoras comercializadoras van tejiendo lazos que les permiten aumentar su capacidad de colocar su producto en el mercado.

Analizando los tipos de lazos existentes entre los actores involucrados en esta red, podría decirse que, aparentemente, el parentesco es un factor fundamental para los lazos fuertes. Sin embargo, se considera que hay otros elementos más determinantes que logran establecerse con el paso del tiempo y con la alta frecuencia de los intercambios, como la confianza, vista como un proceso psico-social, en el cual las partes manifiestan la voluntad de intercambiar beneficios e información. De esa forma, aumentan las posibilidades de sostenerse dentro de la actividad económica. 
La reciprocidad se manifiesta cuando la productora amplía sus ventas y la intermediaria se integra a una actividad que le permite satisfacer sus necesidades mínimas.

Puede valorarse esta red como eficiente por poseer factores que la hacen estable: primero, porque hay vínculos familiares fuertes, madre e hijas, donde los conflictos que se generan son pocos; segundo, porque entre sus miembros se dan seguridad mutua. Por ejemplo, cada una de ellas conoce el puesto de venta del resto de vendedoras y los recorridos que realizan.

En algunos casos de redes entre productora y vendedoras no familiares, hay relaciones entre sus miembros que pueden ser débiles por tratarse de personas que están unidas por un vínculo de ayuda o coordinación, que en un momento determinado se diluye al dejar de pertenecer a dicha red una de las partes. Por ejemplo, cuando hay vendedoras que deciden elaborar ellas mismas los quesillos para comercializarlos, pueden pasar a formar parte de otra red, o bien su propia red de comercialización.

La valoración que las vendedoras dan a esta actividad es alta, porque es una manera de 108 hacer frente a sus necesidades de carácter económico y por la trasmisión de conocimientos que pueden hacer a sus familiares, pues en un futuro, inclusive sus hijas podrán tener una forma de sobrevivir. Sin embargo, este trabajo, tanto para las productoras como las vendedoras ambulantes, representa dificultades por tener que salir de sus casas, relegando actividades domésticas y a sus pequeños hijos.

\subsection{Fortalezas y debilidades de las redes}

La época actual, caracterizada por situaciones económicas, sociales, políticas y culturales complejas, en gran parte determinadas por la globalización, demanda que todo actor analice sus condiciones internas para enfrentar los retos de la realidad. En ese sentido, se estimó conveniente examinar las fortalezas y debilidades de las redes que se conforman en la producción y comercialización del quesillo, entendiendo por fortalezas las capacidades humanas y materiales con las que cuenta la organización y como debilidades, las limitaciones o carencia de habilidades, conocimientos, información, tecnología y recursos financieros de los que adolece.

Dicho análisis se hizo para que en una futura intervención, se incentiven las primeras y se busque la reducción de las segundas, con el propósito de que, a partir de sus potencialidades, se mantengan y consoliden como actividad económica realizada por sectores populares de la sociedad nicaragüense. 
Cuadro 5. Fortalezas y debilidades de las redes sociales que se conforman en la comercialización del quesillo de Nagarote.

\begin{tabular}{|c|c|c|}
\hline Redes sociales & Fortalezas & Debilidades \\
\hline $\begin{array}{l}\text { Redes de } \\
\text { comercialización a } \\
\text { nivel macro. }\end{array}$ & $\begin{array}{l}\text { - Vínculos con alto grado de estabilidad. } \\
\text { - Prácticas con antecedentes de varios } \\
\text { años. } \\
\text { - Claridad respecto a los beneficios } \\
\text { mutuos. } \\
\text { - Producto con tradición cultural. } \\
\text { - Existencia de un mercado establecido. } \\
\text { - Generadoras de empleo. } \\
\text { - Implementación de estrategias para } \\
\text { mejorar el producto. }\end{array}$ & $\begin{array}{l}\text { - Escasos vínculos entre } \\
\text { productoras. } \\
\text { - } \text { Disponibilidad insuficiente de } \\
\text { capital de trabajo. } \\
\text { - } \text { Canales de comercialización } \\
\text { limitados. } \\
\text { - Acopio de leche afectado por las } \\
\text { estaciones del año. } \\
\text { - } \text { Bajo nivel de tecnificación en el } \\
\text { proceso. } \\
\text { - Empleo generado carece de } \\
\text { prestaciones sociales. }\end{array}$ \\
\hline $\begin{array}{l}\text { Redes entre queseros } \\
\text { y productores }\end{array}$ & $\begin{array}{l}\text { - Relaciones de confianza y de } \\
\text { reciprocidad. } \\
\text { - Localización geográfica de la red. } \\
\text { - Apoyo mutuo. }\end{array}$ & $\begin{array}{l}\text { - Los queseros controlan el } \\
\text { abastecimiento en épocas de } \\
\text { escasez. } \\
\text { - Las productoras que integran la } \\
\text { red no tienen vínculos entre sí. }\end{array}$ \\
\hline $\begin{array}{lr}\text { Redes entre } \\
\text { productoras } \quad \mathrm{y} \\
\text { vendedoras. }\end{array}$ & $\begin{array}{l}\text { - Existencia de vínculos tanto familiares } \\
\text { como de amistad y vecindad. } \\
\text { - } \text { Creatividad para la apertura de nuevos } \\
\text { mercados. } \\
\text { - Cercanía física de las actoras. } \\
\text { - En conjunto, tienen un alto volumen } \\
\text { de producción. } \\
\text { - Aprendizaje intergeneracional que } \\
\text { permite la trasmisión de conocimientos } \\
\text { y destrezas. } \\
\text { - Tácitamente existe un acuerdo sobre } \\
\text { el precio y lugares de venta. }\end{array}$ & $\begin{array}{l}\text { - Comercialización a pequeña } \\
\text { escala: ferias, calles y otros } \\
\text { lugares donde hay fuerte } \\
\text { afluencia de personas. } \\
\text { - Formas de comercializar de } \\
\text { manera ambulante que generan } \\
\text { mayores riesgos para las } \\
\text { vendedoras. } \\
\text { - Producto de menor calidad. } \\
\text { - Recursos financieros escasos. }\end{array}$ \\
\hline
\end{tabular}

Fuente: elaboración propia

Haciendo un análisis general, puede observarse en el cuadro 5 que en las redes identificadas hay un número ligeramente mayor de fortalezas que debilidades, en buena medida gracias a las conexiones sociales que logran establecerse entre los integrantes de dichas redes.

\section{Amenazas y oportunidades del entorno}

Las oportunidades son situaciones o factores sociales, económicos, políticos o culturales que están fuera del control de cadenas y redes, pero se pueden aprovechar para el desarrollo; y se consideran amenazas todos los factores externos en los que resulta difícil incidir, sobre todo cuando su naturaleza es estructural, y que podrían perjudicar y/o limitar los avances de la actividad productiva del quesillo (cuadro 6).

La valoración del entorno permitió reconocer factores que, por la influencia que generan, pueden ser considerados tanto amenazas como oportunidades, según la perspectiva de 
análisis, y las estrategias que puedan definirse desde las redes o las organizaciones interesadas en promover el desarrollo de este tipo de empresas.

Cuadro 6. Amenazas y oportunidades en el contexto del comercio del quesillo

\begin{tabular}{|l|l|}
\hline \multicolumn{1}{|c|}{ Amenazas } & \multicolumn{1}{c|}{ Oportunidades } \\
\hline $\begin{array}{l}\text { Inexistencia de proyectos municipales de apoyo } \\
\text { a este sector. }\end{array}$ & $\begin{array}{l}\text { Existencia de una tradición cultural alrededor del } \\
\text { quesillo que garantiza un mercado. }\end{array}$ \\
\hline $\begin{array}{l}\text { Amplia competencia de productos alimenticios en } \\
\text { el mercado, particularmente en los espacios donde } \\
\text { se desarrolla la venta ambulante. }\end{array}$ & $\begin{array}{l}\text { Peculiaridades del sector informal en el país, donde } \\
\text { los requerimientos para desarrollar el comercio } \\
\text { ambulante son mínimos; basta con tener un producto. }\end{array}$ \\
\hline $\begin{array}{l}\text { Altos niveles de inseguridad ciudadana que pone } \\
\text { en riesgo a las vendedoras de la cadena 3. }\end{array}$ & $\begin{array}{l}\text { Geografía económica: alta afluencia vehicular y de } \\
\text { personas en puntos de comercialización que permite } \\
\text { mantener volúmenes de producción. }\end{array}$ \\
\hline $\begin{array}{l}\text { Fuertes exigencias de las organizaciones } \\
\text { financieras para acceder a los créditos. }\end{array}$ & $\begin{array}{l}\text { Existencia de Instituciones y organismos que apoyan } \\
\text { a las Pymes. }\end{array}$ \\
\hline $\begin{array}{l}\text { Escasa cobertura de los organismos de fomento } \\
\text { a las Pequeñas y Medianas Empresas (Pymes). }\end{array}$ & $\begin{array}{l}\text { Definición de Política de fomento a las Pequeñas y } \\
\text { Medianas Empresas (Pymes) por parte de instancias } \\
\text { gubernamentales. }\end{array}$ \\
\hline $\begin{array}{l}\text { Presencia en el mercado de transnacionales que } \\
\text { entran a competir (Área de Libre Comercio de las } \\
\text { Américas-ALCA), encontrándose las micros y } \\
\text { pequeñas productoras en condiciones } \\
\text { desventajosas en cuanto a tecnología y } \\
\text { disponibilidad de recursos. }\end{array}$ & $\begin{array}{l}\text { Impulso del área de libre comercio de las Américas- } \\
\text { productos autóctonos. }\end{array}$ \\
\hline
\end{tabular}

Fuente: elaboración propia

\section{Conclusiones y recomendaciones}

\section{De cara al país}

- En Nicaragua se ha dependido históricamente de modelos de desarrollo propuestos desde fuera, y la mirada en la búsqueda de alternativas ha estado siempre en el exterior. Sin embargo, cuando se conoce la experiencia del quesillo en Nagarote, es necesario reconocer la iniciativa, la creatividad y la constancia, tanto individuales como colectivas, que han logrado la formación de un complejo productivo en el sub-sector lácteo, que no sólo contribuye al desarrollo económico del país, sino también ha creado un producto que es parte de la cultura autóctona. Recomendamos que el gobierno apoye esta iniciativa a través de sus políticas de fomento a las Pymes, para su fortalecimiento en el mercado y para mejorar la calidad de vida de las productoras-comercializadoras de quesillo.

- El quesillo de Nagarote, en tanto que es un producto endógeno, constituye un factor que aporta a las condiciones de Nicaragua como país para enfrentar los retos de la globalización, pues en la medida que existen elementos culturales que se integran a la identidad nacional, los riesgos de ser anulados como nación disminuyen. Como muestran los resultados del estudio, hay un mercado permanente y en crecimiento de este producto, 
considerado como un platillo típico, elaborado completamente con insumos nacionales. Se ha podido visualizar la importancia del papel que juegan los hábitos y las costumbres de una sociedad dada. Desde distintas instancias, sean gubernamentales o no, se debe crear un ambiente favorable para el sector. Es decir: promover eventos como ferias nacionales e internacionales que abran nuevos mercados a los quesillos de Nagarote, particularmente ahora que se valora el turismo como una alternativa para la generación de divisas.

- La ejecución de programas que respondan a una lógica de desarrollo para el fortalecimiento de las potencialidades de los actores de las distintas redes, tendría que partir de los mecanismos ya establecidos por ellos, que funcionan con éxito a lo largo de varias décadas, y son un fundamento indispensable para la consolidación de la producción y comercialización del quesillo.

- La producción y comercialización del quesillo es una actividad fundamentalmente femenina: pequeñas ganaderas productoras de leche, queseras, quesilleras, comerciantes de insumos diversos, tortilleras, vendedoras en puestos fijos y batelleras. Aunque se trata de la elaboración de alimentos, que tradicionalmente es una labor asignada a las mujeres, es un medio que ha permitido a muchas de ellas la independencia económica, ser el sostén de sus familias, tener una posición ocupacional que las ubica como patrona y, por lo tanto, estar en mejores condiciones para tomar decisiones. Finalmente, cabe señalar que este estudio, el primero que aborda la actividad económica y social alrededor de los quesillos, revela a Nicaragua parte de sus fortalezas, puesto que hay iniciativas comerciales surgidas de sectores populares que comúnmente pasan desapercibidas y son generadoras de ingresos que, quizás, ni se incluyen en las cuentas nacionales como parte de su producto interno

Con relación a instituciones de fomento a la producción (gubernamentales y no gubernamentales)

- Las cuatro cadenas identificadas se conformaron como tales sin una previa planificación, como sucede actualmente con los clusters productivos, sino que ha sido la práctica la que ha entretejido un conjunto de relaciones entre una serie de actores que hoy tienen claramente definido un papel en todo el proceso. Hay que reconocer que los sectores populares tienen iniciativas encaminadas a producir y lograr el desarrollo de sus actividades económicas, por lo que tomando en cuenta la importancia económica, social y cultural de los resultados de este estudio, se espera que contribuya al análisis que fundamente las políticas comerciales para ampliar la cobertura de las Políticas de Fomento a las Pymes que deben abarcar a todos los subsectores económicos, incluyendo el quesillo de Nagarote.

\section{Dirigidas a instancias académicas}

- Hacer visibles las interconexiones entre una diversidad de actores aparentemente vinculados para llevar a cabo una actividad comercial, ha permitido comprobar que, tras ese proceso, hay toda una dinámica social basada en lazos situados más allá de lo 
meramente mercantil, que los modelos de análisis economistas generalmente dejan fuera. Por lo tanto, es necesario llevar a cabo otros estudios que aborden experiencias de comercialización, con énfasis en las relaciones sociales que las impulsan y mantienen.

\section{Con respecto a las productoras - comercializadoras}

- Se identificó la carencia de una organización formal de productoras-comercializadoras de quesillo, lo que les impide demandar, ante diversas instancias, mejoras para fortalecer su actividad. Sin embargo, es una realidad la asociación de estas mujeres productoras de quesillos quienes, para elaborar y vender su producto en los distintos puntos conquistados del mercado nacional, generan respuestas efectivas a los problemas y necesidades de trabajo que se les presentan, utilizando el capital relacional que les facilita el acceso a recursos materiales y humanos. Por lo tanto, se considera que el gobierno local es otro actor con responsabilidad para la búsqueda del fortalecimiento de esta actividad económica y le corresponde impulsar iniciativas para que la organización de los distintos actores de las cadenas sea efectiva, estableciendo grupos de discusión,

112 ya que las personas generadoras de ideas forjadas en su realidad y experiencias son quienes pueden identificar las mejores soluciones.

\section{Notas}

3. Según versión de algunas personas mayores de Nagarote, esta señora residia en una finca ganadera del lugar y, en la búsqueda de un mayor aprovechamiento de la producción lechera, experimentó con la cuajada, obteniendo los resultados apuntados. El quesillo originalmente se vendía en hojas de "chagüite".

\section{Referencias bibliográficas}

-LOMNITZ, L. (1985). Como sobreviven los marginados. México. Siglo XXI.

-LOZARES, C. (1996). Curso de especialización de post-licenciatura en Centroamérica, (postgrado en formación de formadores(as) sociales: asesoramiento curricular y metodológico Junio-Julio UCA, Managua.

-DAVIDE, P. (2001). "Análisis sub sectorial en la rama de cuero/calzado de Nicaragua en 2000”. Cuaderno de investigación No. 14 Nitlapán-UCA, Managua, Nicaragua.

-PRATT, H. (1944). Diccionario de Sociología, México,

Programa regional de empleo para América Latina y el Caribe -PREALC(1986) Cambio y polarización ocupacional en Centroamérica. Costa Rica 